\title{
STUDY OF BIOLOGICAL EFFECTS WHEN EXPOSURE TO He-Ne LASER AND UVC RADIATION ON HEAD SPERM ABNORMALITIES IN MICE
}

\author{
AKRAM R.S. ${ }^{1}$, NAMMUK F.N. ${ }^{1}$ AND AHMED S.J. ${ }^{*}$ \\ ${ }^{1}$ Medical Physics, College of Medicine, Baghdad University, Baghdad, Iraq. \\ 2Anatomy Department, College of Medicine, Baghdad University, Baghdad, Iraq. \\ ${ }^{*}$ Corresponding Author: Email- shaymajamal@yahoo.com
}

Received: September 12, 2013; Accepted: September 25, 2013

\begin{abstract}
In vitro, He-Ne laser show a modifying response of cells to ionizing radiations. So there is a need to show the effect of He-Ne laser $(632.8 \mathrm{~nm})$, Ultraviolet radiation UVC $(250 \mathrm{~nm})$ and He-Ne laser pre and post irradiation against the UVC radiation in vivo on sperm morphology of testis in Mice.

In this study 100 albino male mice were divided into five groups, the first group is control which have (10) number of mice, the second group is Laser which have (27) number of mice were divided into three groups different time periods $(5,10,15 \mathrm{~min})$, the third group is Ultraviolet radiation (UVC) which have (9) number of mice and duration of exposure one hour, the fourth is group laser (5, 10 and $15 \mathrm{~min})+\mathrm{UVC}(1 \mathrm{hr}$.) which have (27) number of mice, with $1 / 2 \mathrm{hr}$. time interval between the two irradiations and the finally group is UVC (1 hr.) + laser $(5,10,15 \mathrm{~min})$ which have (27) number of mice, with $1 / 2 \mathrm{hr}$. time interval between the two irradiations was monitor the effect of radiation on mice according to the classification totals above after various time periods $(7,14,21$ days).

Four sperm head abnormality features were found after each type of irradiation. But the He-Ne laser pre-irradiation against UVC irradiation lower the frequencies of sperm head abnormalities.

Both UVC and He-Ne laser irradiations revealed a toxic effect on sperm head morphology, but the He-Ne laser was found less effective. The $\mathrm{He}-\mathrm{Ne}$ laser per-irradiation show a protection properties, which appeared on both sperm head abnormalities and the protective properties were observed only when He-Ne laser irradiation was applied before the UVC irradiation.
\end{abstract}

Keywords- He-Ne laser, Ultraviolet radiation UVC, radiation, sperm head abnormalities, mice

Citation: Akram R.S., Nammuk F.N. and Ahmed S.J. (2013) Study of Biological Effects When Exposure to He-Ne Laser and UVC Radiation on Head Sperm Abnormalities in Mice. International Journal of Medical and Clinical Research, ISSN: 0976-5530 \& E-ISSN: 0976-5549, Volume 4, Issue 2, pp.-269-273.

Copyright: Copyright@2013 Akram R.S., et al. This is an open-access article distributed under the terms of the Creative Commons Attribution License, which permits unrestricted use, distribution and reproduction in any medium, provided the original author and source are credited.

\section{Introduction}

Laser is a widely used device in the medical field. In vivo effect of singular and repeated exposure of laser beam on a mammalian model was studied to ascertain any possible effect on mammalian germ cells. Since agents considered to be mutagenic affect sperm head shape, sperm morphology study may be an applicable screen for laser effects on germ cells [1].

Low level laser therapy (LLLT) is a light source treatment that generates light of a single wavelength. LLLT emits no heat, sound, or vibration. Instead of producing a thermal effect, LLLT may act via non thermal or photochemical reactions in the cells, also referred to as photobiology or biostimulation [2].

In other hand (LLLT) is the application of light (usually a low power laser or LED in the range of 1-500 $\mathrm{mW}$ ) to a pathology to promote tissue regeneration, reduce inflammation and relieve pain. The light is typically of narrow spectral width in the red or near infrared (NIR) spectrum (600-1000 nm), light is absorbed and exerts a chemical change [3].
UV radiation has clear effects on organisms, it causes several biological reaction, through the generation of the free radicals and the reactive Oxygen species (ROS), formed by various photochemical processes. The free radicals induces a sequences of events including lipid peroxidation, proteins denaturation and deoxyribonucleic acid( DNA) changes [4], the DNA changes are the single strand breaks (ssB) and the double strand breaks (dsB)" or cell damage [5].

Scientists classify UV radiation into three types or bands - UVA, UVB, and UVC. The ozone layer absorbs some, but not all, of these types of UV radiation [6]:

- UVA: Wavelength: $320-400 \mathrm{~nm}$. Not absorbed by the ozone layer.

- UVB: Wavelength: 290-320 nm. Mostly absorbed by the ozone layer, but some does the reach the Earth's surface.

- UVC: Wavelength: 100-290 $\mathrm{nm}$. Completely absorbed by the ozone layer and atmosphere. 


\section{Materials and Methods}

In the current study, the He-Ne laser, UVC doses, and the separation time between the two irradiation are kept fixed. The UVC lamp from Industrial Fiber Optics of $250 \mathrm{~nm}$ wavelength, and a power of 20 Watt (W) was used. The He-Ne laser of wavelength $632.8 \mathrm{~nm}$ with a maximum output power of $1.0 \mathrm{~mW}$ (Industrial Fiber Optics IFHIV) was employed.

\section{Animals Experiments}

In order to assess the influence of He-Ne laser plus the UVC irradiation on testis of Mice the following experiments were performed. 100 adult of albino male mice, were used in this study and were divided into five groups and irradiation as in [Table-1].

1. First Group: the animals normal, which was control group.

2. Second Group: was used to characterize the degree of UVC $(250 \mathrm{~nm})$ irradiation on mice testis. The UVC source placed at $30 \mathrm{~cm}$ above the mouse cage, where the final UVC power at the mouse skin surface was $1.2 \mathrm{~mW}$ for $1 \mathrm{hr}$.

3. Third Group: was employed to study the influence of $\mathrm{He}-\mathrm{Ne}$ laser irradiation. A continuous He-Ne laser of wavelength 632.8 $\mathrm{nm}$ with a maximum output power of $1.0 \mathrm{~mW}$ and a beam diameter of $3 \mathrm{~mm}$, was employed. The laser beam was directed on testis for a period of $(5,10,15 \mathrm{~min})$, which equal to energy dose of $\left(4.2 \mathrm{~J} / \mathrm{cm}^{2}, 8.4 \mathrm{~J} / \mathrm{cm}^{2}\right.$ and $\left.12.6 \mathrm{~J} / \mathrm{m}^{2}\right)$.

4. Fourth Group: was pre-irradiated by He-Ne laser $\left(4.2 \mathrm{~J} / \mathrm{cm}^{2}\right.$, $8.4 \mathrm{~J} / \mathrm{cm}^{2}$ and $\left.12.6 \mathrm{~J} / \mathrm{cm}^{2}\right)$ for $(5,10,15 \mathrm{~min})$ followed by UVC irradiation, with one hour and wait for $1 / 2 \mathrm{hr}$. time (for UVC) interval between the two irradiations.
5. Fifth Group: was pre-irradiated by UVC light with one hour wait for $1 / 2 \mathrm{hr}$. time, this group was irradiated by $\mathrm{He}-\mathrm{Ne}(5,10,15$ min) laser of $\left(4.2 \mathrm{~J} / \mathrm{cm}^{2}, 8.4 \mathrm{~J} / \mathrm{cm}^{2}\right.$ and $\left.12.6 \mathrm{~J} / \mathrm{cm}^{2}\right)$, the laser beam was directed on testis.

Table 1- Animals which used in this study

\begin{tabular}{|llccc|}
\hline \multirow{2}{*}{ No } & Type of Radiation & \multicolumn{3}{c}{ Number of animals after } \\
& & 7 days & 14 days & 21 days \\
\hline 1 & Control & 10 & & \\
\hline 2 & UVC (1 hr.) & 3 & 3 & 3 \\
\hline 3 & (a) Laser $(5 \mathrm{~min})$ & 3 & 3 & 3 \\
& (b) Laser (10 min) & 3 & 3 & 3 \\
& (c) Laser (15 min) & 3 & 3 & 3 \\
\hline 4 & (a) Laser $(5 \mathrm{~min})+$ UVC $(1 \mathrm{hr})$. & 3 & 3 & 3 \\
& (b) Laser (10 min) + UVC (1 hr.) & 3 & 3 & 3 \\
& (c) Laser (15 min) + UVC (1 hr.) & 3 & 3 & 3 \\
\hline 5 & (a) UVC (1 hr.) + Laser (5 min) & 3 & 3 & 3 \\
& (b) UVC (1 hr.) + Laser (10 min) & 3 & 3 & 3 \\
& (c) UVC (1 hr.) + Laser (15 min) & 3 & 3 & 3 \\
\hline
\end{tabular}

\section{Sperm Head Abnormalities}

Animals were sacrificed, after 15 min of the final irradiation, according to Banerjee method through cervical dislocation [1]. This examination was according to Wyrobek and Bruce [7].

\section{Results}

To study the sperm head abnormalities when exposure to radiation which are summarized in the [Table-2] and the abnormal sperm head features found in this study are illustrated in [Fig-1a], [Fig-1b], [Fig-1c], [Fig-1d] and [Fig-1e].

Table 2- The Mean $\pm S D$ of sperm head abnormalities

\begin{tabular}{|c|c|c|c|c|c|}
\hline Type of radiation & Normal Mean \pm SD & No head Mean \pm SD & Balloon Mean \pm SD & Thread Mean \pm SD & Curved head $\&$ No hook Mean \pm SD \\
\hline Control & $91.67 \pm 1.528$ & 0 & 0 & 0 & 0 \\
\hline UVC (1 hr.) & $42.33 \pm 2.517$ & $20.67 \pm 8.145$ & $18.67 \pm 4.041$ & $7.67 \pm 2.517$ & $10.67 \pm 8.145$ \\
\hline Laser (5 min) & $44.33 \pm 5.132$ & $18.33 \pm 5.774$ & $20.00 \pm .000$ & $8.33 \pm 1.528$ & $12.33 \pm 6.429$ \\
\hline Laser (10 min) & $48.67 \pm 6.110$ & $17.67 \pm 4.619$ & $15.67 \pm 4.041$ & $6.00 \pm 2.000$ & $12.00 \pm 4.359$ \\
\hline Laser (15 $\mathrm{min})$ & $52.67 \pm 1.015$ & $16.67 \pm 2.887$ & $12.33 \pm 6.807$ & $6.67 \pm 2.887$ & $11.67 \pm 1.528$ \\
\hline Laser (5 min) + UVC (1 hr.) & $46.33 \pm 5.508$ & $12.67 \pm 5.859$ & $22.00 \pm 9.849$ & $5.67 \pm 1.155$ & $13.33 \pm 2.887$ \\
\hline Laser (15min) + UVC (1 hr.) & $37.33 \pm 11.240$ & $21.67 \pm 8.505$ & $15.67 \pm 1.155$ & $11.00 \pm 3.606$ & $14.33 \pm 1.155$ \\
\hline UVC (1 hr.) + Laser (5 min) & $41.67 \pm 2.887$ & $20.00 \pm 5.000$ & $15.00 \pm 5.000$ & $7.33 \pm 2.517$ & $16.00 \pm 3.606$ \\
\hline UVC (1 hr.) + Laser (10 min) & $48.33 \pm 5.774$ & $16.67 \pm 2.887$ & $15.67 \pm 4.041$ & $5.67 \pm 1.155$ & $17.00 \pm 3.606$ \\
\hline UVC (1 hr.) + Laser (15 min) & $39.00 \pm 6.928$ & $16.00 \pm 1.732$ & $19.00 \pm 1.732$ & $11.00 \pm 3.606$ & $15.00 \pm 5.000$ \\
\hline
\end{tabular}

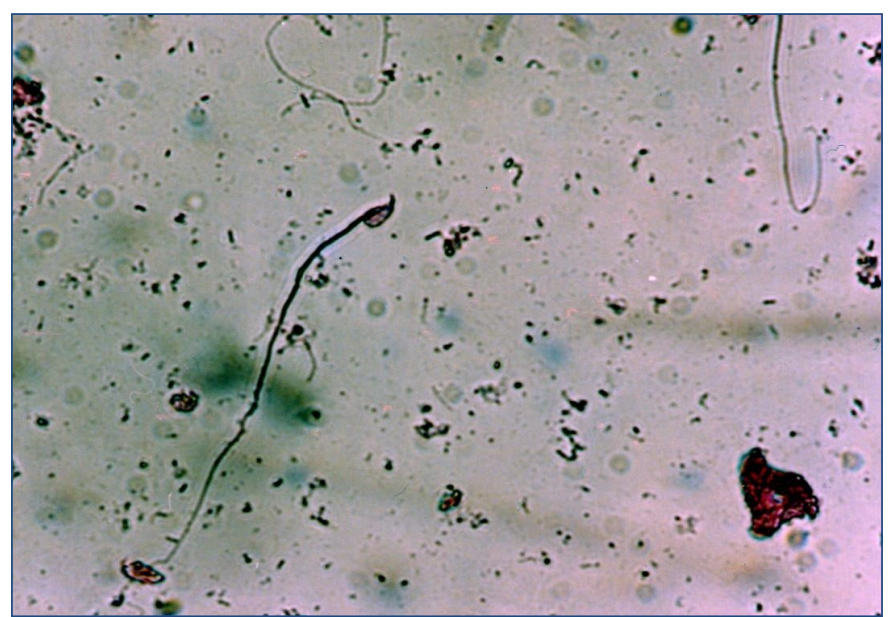

Fig. 1a- Normal sperm

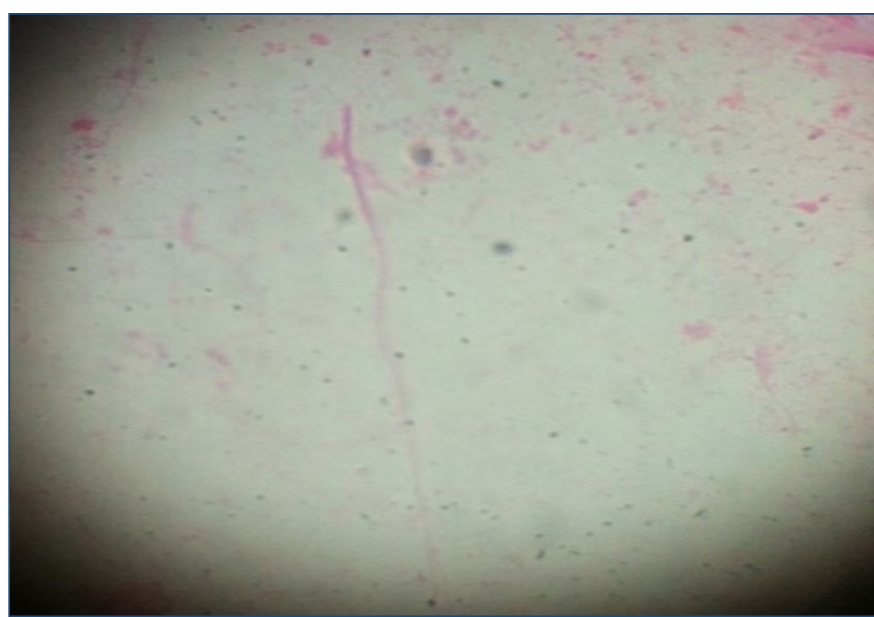

Fig. 1b- No head sperm 


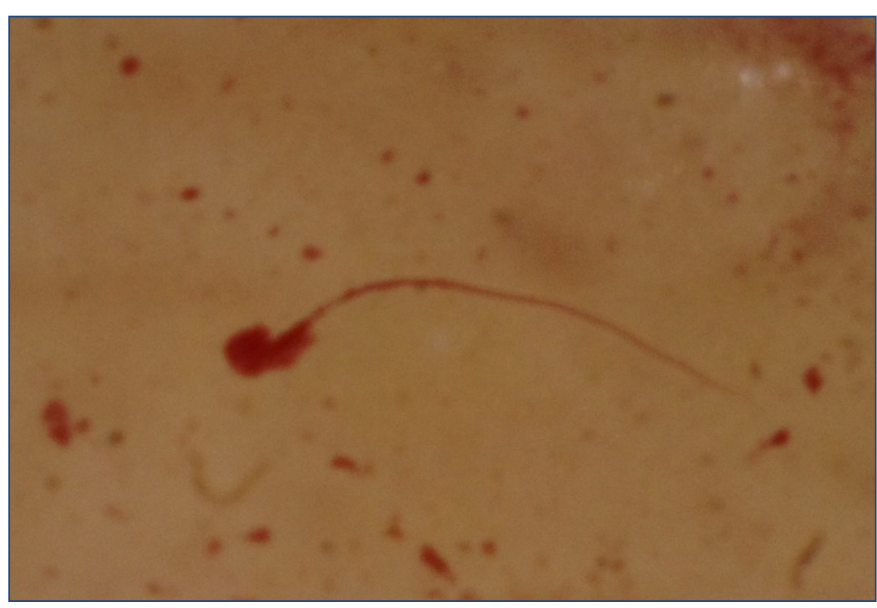

Fig. 1c- Balloon sperm

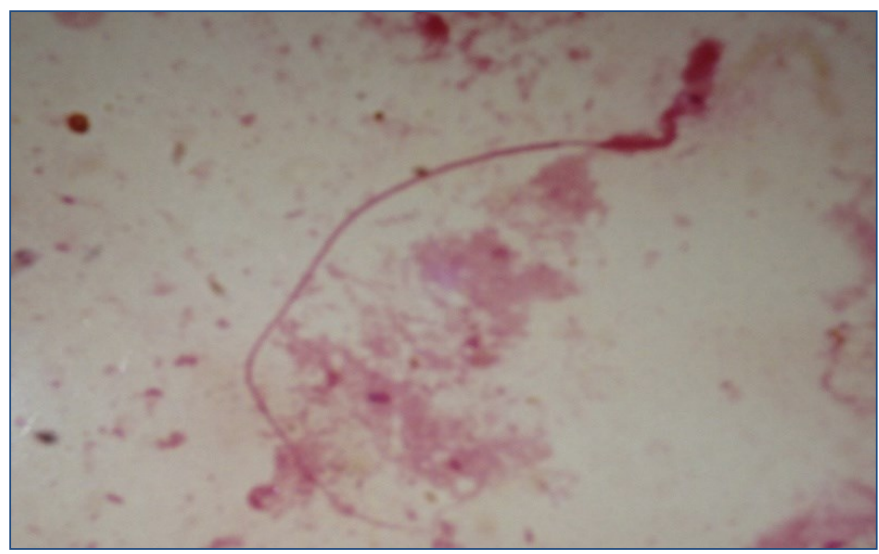

Fig. 1d- Thread sperm

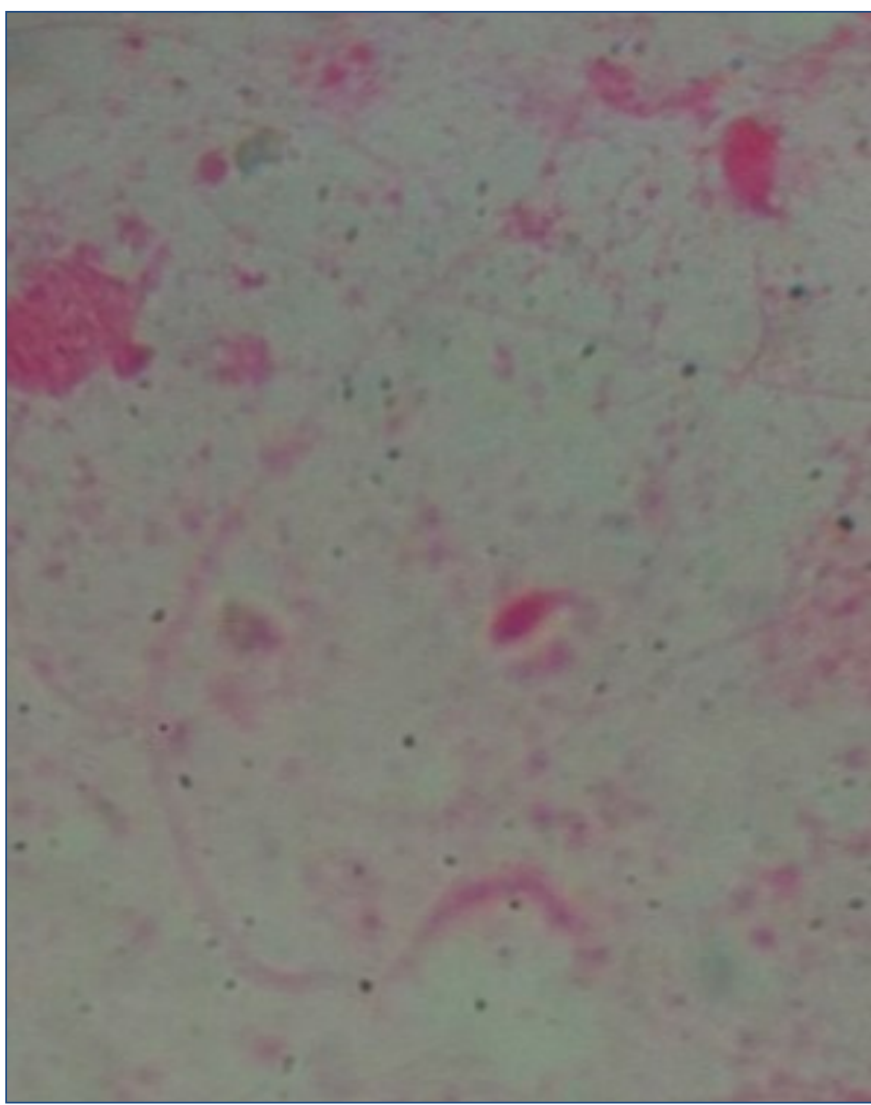

Fig. 1e- Curved head \& No hook sperm.

\section{Discussion}

He-Ne laser show a modifying response of cells to ionizing radiations. So there is a need to investigate this property In vivo. To investigate the effect of $\mathrm{He}-\mathrm{Ne}$ laser $(632.8 \mathrm{~nm})$ pre and post irradiation against the UVC $(250 \mathrm{~nm})$ irradiation In vivo on the sperm morphology. In this study there are four sperm head abnormalities: no head, thread head, balloon head and curved head \& no hook [Fig1]. [Table-2] show the Mean $\pm S D$ of sperm head abnormalities in all types of radiation.

In UVC (1 hr.) the highest Mean \pm SD shown in No head sperm (20.67 \pm 8.145$)$, Balloon head (18.67 \pm 4.041$)$, Curved head \& No hook (10.67 \pm 8.145$)$ and Thread head $(7.67 \pm 2.517)$, the correlation between UVC ( $1 \mathrm{hr}$.) and No head, Thread is no significant but correlation between UVC (1 hr.) and Balloon, Curved is significant. The table also clarify that $\mathrm{He}-\mathrm{Ne}$ laser $(5,10,15 \mathrm{~min})$ irradiation lead to some degree of sperm head abnormalities. This mean that, the used $\mathrm{He}$-Ne laser dose in this work reveled a toxic effect. In laser $(5 \mathrm{~min}$ ) the highest Mean $\pm \mathrm{SD}$ shown in Balloon head (20.00 $\pm .000)$, No head $(18.33 \pm 5.774)$, Curved head \& No hook (12.33 \pm 6.429) and Thread head $(8.33 \pm 1.528)$. In laser (10 min) the highest Mean \pm SD shown in No head (17.67 \pm 4.619$)$, Balloon head $(15.67 \pm 4.041)$, Curved head \& No hook (12.00 \pm 4.359$)$ and Thread head $(6.00 \pm 2.000)$. In laser $(15 \mathrm{~min})$ the highest Mean \pm SD shown in No head (16.67 \pm 2.887 ), Balloon head (12.33 \pm 6.807), Curved head \& No hook (11.67 \pm 1.528$)$ and Thread head (6.67 \pm 2.887$)$. The highest value of laser $(5,10,15 \mathrm{~min})$ Balloon head $(20.00 \pm .000)$, No head $(18.33 \pm 5.774)$, Curved head \& No hook (12.33 \pm 6.429$)$ and Thread head $(8.33 \pm 1.528)$, the correlation among laser $(5,10,15 \mathrm{~min})$ and No head, Balloon, Thread is no significant but the correlation among laser $(5,10,15 \mathrm{~min})$ and Curved is significant. He-Ne laser $(5,10,15 \mathrm{~min})$ pre-irradiation against UVC (1 hr.) irradiation show. In laser (5 min) + UVC (1 hr.) the highest Mean $\pm S D$ shown in Balloon head $(22.00 \pm 9.849)$, Curved head \& No hook (13.33 \pm 2.887$)$, No head $(12.67 \pm 5.859)$ and Thread head $(5.67 \pm 1.155)$, the correlation among laser (5 $\mathrm{min})+$ UVC (1 hr.) and No head, Balloon is no significant but the correlation among laser (5 min) + UVC (1 hr.) and Thread, Curved is significant.

Globozoospermia (round-headed sperm) a modest increase in the frequency of sex chromosome aneuploidy (2-3 times that in controls) had been found in the sperm of patients with globozoospermia (round-headed sperm) [8-13]. Globozoospermia is a very rare condition observed in $<1 \%$ of infertile patients, where the major morphological anomaly is the absence of an acrosomal cap in sperm. There is also some suggestion that globozoospermia may be associated with abnormalities in chromatin structure since an increased frequency of sperm with DNA strand breaks has been found in these patients [11], but this has not been observed in all studies [14]. Mouse models may permit exploration of the mechanisms leading to the abnormalities in this disorder [15].

In laser (10 min) + UVC (1 hr.) the highest Mean \pm SD shown in Balloon head (18.33 \pm 2.887$)$, No head $(15.00 \pm .000)$, Curved head \& No hook (14.00 \pm 1.732$)$ and Thread head (11.67 \pm 2.887$)$. In laser (15 min) + UVC (1 hr.) the highest Mean \pm SD shown in No head (21.67 \pm 8.505$)$, Balloon head $(15.67 \pm 1.155)$, Curved head $\&$ No hook (14.33 \pm 1.155$)$ and Thread $(11.00 \pm 3.606)$. The highest value of laser (5, 10, $15 \mathrm{~min})+\mathrm{UV}$ ( $1 \mathrm{hr}$.) Balloon head (22.00 \pm 9.849), No head (21.67 \pm 8.505$)$, Curved head \& No hook (14.33 \pm 1.155) and Thread head (11.67 \pm 2.887$)$, the correlation among 
laser $(10,15 \mathrm{~min})+$ UVC (1 hr.) and No head, Thread is no significant but the correlation among laser (10 min) + UVC (1 hr.) and Balloon, Curved is significant.

When He-Ne laser $(5,10,15 \mathrm{~min})$ performed post UVC (1 hr.) irradiation the Mean \pm SD of UVC (1 hr.) + laser (5, 10, $15 \mathrm{~min})$. In UVC (1 hr.) + laser (5 min) the highest Mean \pm SD shown in No head $(20.00 \pm 5.000)$, Curved head \& No hook $(16.00 \pm 3.606)$, Balloon head (15.00 \pm 5.000$)$ and Thread head $(7.33 \pm 2.517)$, the correlation among UVC (1 hr.) + laser ( $5 \mathrm{~min})$ and No head, Thread is no significant but the correlation among UVC (1 hr.) + laser (5 $\mathrm{min}$ ) and Balloon, Curved is significant. In UVC (1 hr.) + laser (10 min) the highest Mean \pm SD shown in Curved head \& No hook (17.00 \pm 3.606$)$, No head (16.67 \pm 2.887$)$, Balloon head (15.67 \pm 4.041) and Thread head (5.67 \pm 1.155$)$, the correlation among UVC $(1 \mathrm{hr})+$. laser (10 min) and No head, Balloon, Thread is significant but the correlation between UVC (1 hr.) + laser (10 min) and Curved is no significant. In UVC (1 hr.) + laser (15 min) the highest Mean \pm SD shown in Balloon head (19.00 \pm 1.732$)$, No head (16.00 \pm 1.732), Curved head \& No hook (15.00 \pm 5.000$)$ and Thread head $(11.00 \pm 3.606)$. The highest value of UVC (1 hr.) + laser $(5,10,15$ min) No head (20.00 \pm 5.000$)$, Balloon head (19.00 \pm 1.732$)$, Curved head \& No hook (17.00 \pm 3.606$)$ and Thread head (11.00 \pm 3.606), the correlation among UVC (1 hr.) + laser (15 min) and No head, Thread, Curved is significant but the correlation between UVC (1 hr.) + laser (15 min) and Balloon is no significant.

When Swiss Albino mice were exposed to laser beam, then significant (at both 1\% and 5\% levels) morphological changes of sperm heads occurred and increased with repetitive exposure. Also, normal sperm count decreased. It is suggested that laser may have an adverse effect on male germ cells [1].

Globozoospermia where the sperm head appears small and round due to the failure of the acrosome to develop, is an example of a head defect. Middle piece defects include 'bent' neck (where the neck and tail form an angle of greater than $90 \%$ to the long axis of the head), asymmetrical insertion of the middle piece into the head, a thick or irregular middle piece, an abnormally thin middle piece (with no mitochondrial sheath), as well as any combination of these. Tail defects include short, multiple, hairpin, broken or bent $\left(>90^{\circ}\right)$ tails, tails of irregular width, coiled tails, as well as any combination of these [16].

Separation of the sperm head and tail can be caused by a number of adverse factors affecting either spermiogenesis or sperm maturation [17]. However, a specific, sterilizing form has been reported in several cattle breeds (Guernsey, Hereford, Swedish Red \& White) where it has been associated with sterility.

Both the nuclear crest and rolled head defects were also reported to be caused by ethylene-dibromide spermatoxicity [18]. Although effects of this sperm defect upon fertility are unclear [17], it is logical to assume that abnormal chromosome numbers in sperm would compromise fertility, as encountered in males with Kleinfelter's syndrome [19].

The UVC radiation is sufficiently energetic that individual photons may produce chemical bond breakage and ionization of some atoms and molecules. The preferential absorption of particular energy photons by materials, both organic and inorganic, is evident throughout the electromagnetic spectrum from microwaves through infrared and visible light, Ultraviolet, X-rays, and Gamma rays [20]. Since spermatogenesis is a complex cytomorphological event con- trolled by various sets of genes and their products. The final shape and size of spermatozoon in a species being determined at the very late phase of spermiogenes [21], So changes in sperm head morphology may be an applicable screen for radiation exposure doses effect on germ cells and events of late phase of spermiogenesis. This He-Ne laser toxic properties was reported by Banerjee, et al [1] on sperm head morphology of mice and also by Taha, et al [22] on lymphocyte cells survival and it's DNA damage.

It can be concluded that, He-Ne laser irradiation by it self show a toxic effect leading to some degree of sperm head abnormalities. While He-Ne laser pre ionizing irradiation (UVC) may be resulting in adversely influncing mammalian germ cell metabolism, which lowering the frequencies of sperm head abnormalities [23].

The mechanism of the He-Ne laser induce protection appears to be a sort of adaptive response. He-Ne laser irradiation has been reported to lead to the generation of single Oxygen species and also increase the activity of the antioxidant enzymes $[24,25]$. Conclusion UVC shows a damaging effect on the DNA. This damage was reduced by the He-Ne laser pre- irradiation. Thus Laser pre-irradiation may be attributed to the induction of endogenous of radio protectors or which may be involved in DNA damage repair.

\section{References}

[1] Banerjee S., Chakrabarti C.S. and Samanta L.K. (2005) Asian J. Exp. Sci., 19, 131-140.

[2] Bjordal J.M., Lopes-Martins R.A., Joensen J., Couppe C., Ljunggren A.E., Stergioulas A. and Johnson M.I. (2001) Physical Therapy Reviews, 6, 91-99.

[3] Huang Y.Y., Chen A.C., Carroll D.J., Hamblin M.R. (2009) Dose Response, 7(4), 358-383.

[4] Cavalcante A.K.D., Martinez G.R., Mascio P.D., Menck C.F., Agnez-Lima L.F. (2002) DNA Repair, 1, 1051-1056.

[5] Wojcik A., Bochenek A., Lankoff A., Lisowska H., Pasjas A., Szumiel I., Sonntag C.V., Obe G. (2006) Journal of Photochemistry and Photobiology B: Biology, 84(1), 15-20.

[6] Environmental Protection Agency (2010) Air and Radiation 6205J, EPA: United States.

[7] Wyrobek A.J. and Bruce W.R. (1975) Natl. Acad. Sci. USA, 72, 4425-4429.

[8] Carrell D.T., Emery B.R., Liu L. (1999) Fertil. Steril., 71(3), 511516.

[9] Carrell D.T., Wilcox A.L., Udoff L.C., Thorp C. (2001) Fertil. Steril., 76, 1258-1260.

[10]Zeyneloglu H.B., Baltaci V., Duran H.E., Erdemli E., Batioglu S. (2002) Hum. Reprod., 17(7), 1833-1836.

[11]Vicari E., Perdichizzi A., De Palma A., Burrello N., D'Agata R., Calogero A.E. (2002) Hum. Reprod., 17(8), 2128-2133.

[12]Martin R.H., Greene C., Rademaker A. (2003) Fertil. Steril., 79, 1662-1664.

[13]Morel F., Douet-Guilbert N., Moerman A., Duban B., Marchetti C., Delobel B., Le Bris M.J., Amice V., De Braekeleer M. (2004) Mol. Hum. Reprod., 10(11), 835-838.

[14]Baccett B., Collodel G., Piomboni P. (1996) J. Submicrosc. Cytol. Pathol., 28, 587-596.

[15]Kang-Decker N., Mantchev G.T., Juneja S.C., McNiven M.A., van Deursen J.M. (2001) Science, 294, 1531-1533. 
[16]Martin R.H., Ko E., Barclay L. (1994) Mutat. Res., 143, 109-112.

[17]Barth A.D., Oko R.J. (1989) Abnormal Morphology of Bovine Spermatozoa, lowa State Press, Ames, IA.

[18]Eljack A.H. and Hrudka F. (1979) J. Ultrastruct. Res., 7, 124134.

[19]Lanfranco F., Kamischke A., ZitzmannM., Nieschlag E. (2004) Lancet, 364, 273-283.

[20]Health Physics Society (1956) Specialists in Radiation Safety, HPS.

[21]Rao D.V., Narra V.R., Howell R.W., Lank V.K. and Sastry K.S.R. (1991) Radiation Research, 125, 89-97.

[22]Taha J.H., Al-Ani F.S., Al-Siaidy W.F. (2012) J. Fac. Med. Baghdad, 54(3), 247-251.

[23]Ahmed S.J., Al-Siaidy W.F. and Faraj R.A. (2013) Journal of Pharmacy and Biological Sciences, 5(1), 09-13.

[24]Kohli R., Bose B., Gupta P.K. (2001) Journal of Photochemistry and Photobiology B: Biology, 60, 136-142.

[25]Radinova L.P., Concharova L.L., Ushova I.N. (1986) Chem. Abstracts, 106, 46-52. 